\title{
Placing nanoplastics in the context of global plastic pollution
}

Denise M. Mitrano ${ }^{1 *}$, Peter Wick ${ }^{2}$, Bernd Nowack ${ }^{3}$

${ }^{1}$ Department of Environmental Systems Science, ETH Zurich, 8092, Zürich, Switzerland

${ }^{2}$ Particles-Biology Interactions Laboratory, Empa - Swiss Federal Laboratories for Materials Science and Technology, Lerchenfeldstrasse 5, 9014 St. Gallen, Switzerland

${ }^{3}$ Technology and Society Laboratory, Empa - Swiss Federal Laboratories for Materials Science and Technology, Lerchenfeldstrasse 5, 9014 St. Gallen, Switzerland

*Corresponding author: Denise.mitrano@usys.ethz.ch

\section{Accepted version of paper published:}

Mitrano, D.M., Wick, P. \& Nowack, B. Placing nanoplastics in the context of global plastic pollution. Nat. Nanotechnol. (2021). https://doi.org/10.1038/s41565-021-00888-2 


\begin{abstract}
Numerous studies have made the ubiquitous presence of plastic in the environment undeniable, and thus it no longer comes as a surprise when scientists measure the accumulation of macroplastic litter and microplastic fragments in both urban and remote sites. Nanoplastics have recently emerged in the discussions of scientists, regulators and the public as the weathering of macroplastics may lead to a substantial burden of nanoplastics in various ecosystems. While nanoplastics particles themselves have not (yet) been extensively measured in the environment, there is increased concern that this size fraction of plastic may be more extensively distributed and hazardous than larger sized particles. This assessment may emanate from an unease with the term "nano", which may elicit a negative response over uncertainties of the pervasiveness of nanoplastics specifically, or from the lessons learned by many years of intensive environmental health and safety research of engineered nanomaterials. Ultimately, the different physical and chemical characteristics of the different size classes of plastic pollution (macroplastics, microplastics and nanoplastics) will result in divergent fate and hazards. As nanoscientists specializing in understanding the fate, transport and interactions of nanoparticles in human and environmental systems, in this perspective we try to place nanoplastics in the context of global plastic pollution by assessing its source and risk, but also by assessing commonalities nanoplastics may share with other nano-sized objects in environmental systems, such as engineered nanomaterials and natural colloids.
\end{abstract}

The magnitude of mismanaged microplastic waste seen around the globe has been a clear indicator of the impacts humans have on the environment and brought forward urgent discussions on how we may be able to live more sustainably. The release of plastic from many diffuse sources is anticipated to negatively impact the water quality of lakes, rivers and oceans as well as soil ecosystems, but our understanding of how particulate plastic behaves in different environmental compartments is still fragmentary. The dominant fraction of particulate plastic originates from the breakdown of macroplastic litter or is released during product use (e.g. fibers from textiles or tire wear), ${ }^{1}$ and conceptually there is no reason why plastic could not fragment further to the nano-size range. Indeed, this has already been shown to occur in laboratory experiments. ${ }^{2,3}$ Therefore, it is difficult to disentangle the various facets of plastic pollution - which could be considered as a continuum from macroplastics to microplastics to nanoplastics. However, it remains unclear if nanoplastics can really simply be considered as an extension of the (micro)plastic problem, given that the difference in particle size may ultimately impart different interactions with organisms and fate and transport pathways, as well as requiring different analytical tools and skill sets to detect and characterize particles in this size range. Consequently, assessing impacts of nanoplastics to environmental systems may be fundamentally different than assessing impacts of macro- or microplastics.

More and more focus is being given to nanoplastics particles, potentially because the word "nano" itself is charged, where the small particle size conjures up an underlying discomfort with nano-sized materials as a whole (e.g. distrust in new nanotechnologies, potential for increased hazards with smaller particles), or because analyzing nanomaterials is considered more of a scientific challenge (e.g. more sophisticated tools and techniques are needed to study them). Both of these aspects have been observed before when assessing the environmental health and safety of engineered nanomaterials. But given the ubiquity of nano-sized particles of natural origin or those unintentionally produced by human activity, e.g. combustion by-products, it is unclear how nanoplastics fit into this picture as they constitute only one class of nanoparticulate material amongst many others of different origins. The experience gained with engineered nanomaterials may shed light on how to approach environmental nanoplastics research as many scientists have transitioned between these two disciplines. However, extrapolations between groups of nanomaterials with known specific toxic properties and modes of action can not necessarily be transferred one to one to the field of nanoplastics without careful considerations of particle chemistry, transport processes and toxicodynamics. To date there is not enough information to perform a proper risk assessment of nanoplastics and thus there are key knowledge gaps that 
still must be filled in terms of both nanoplastic hazard and exposure. Ultimately, we hope to learn from previous experiences on how to assess human and environmental risks to nanosized materials, so that we can better place nanoplastics in context with global plastic pollution.

In this perspective, we explore and discuss how the nanoplastics topic is perceived in the scientific community and society, what are the influencing factors which trigger research and public awareness to understand the consequences of nanoplastics pollution and how we can avoid misleading or dead-end debates. In particular, we examine 1) the prominence of nanoplastics as an environmental contaminant of emerging concern, 2) the implications and challenges with defining nanoplastics, 3) the role of plastic size and chemistry in its environmental fate and impacts in relation with other nano-sized objects, 4) the increased attention by connecting the words "plastic" and "nano" and finally 5) the approaches we as responsible nanoscientists can take in providing evidenced-based assessments of nanoplastics in the context of global plastic pollution.

\section{Nanoplastic as an environmental contaminant of emerging concern}

Contaminants of emerging concern is a term used to describe pollutants that have been detected in the environment which may cause adverse ecological or human health impacts, and typically are not regulated under current environmental laws. The group of substances collectively falling within this description has historically been a moving target, which began with global lead contamination from the Romans two millennia ago, to DDT and chlorofluorocarbons at the start of the environmental movement in the 1960s and more recently includes pharmaceuticals, flame retardants and engineered nanomaterials. ${ }^{4}$ Today, plastic pollution is a major issue and challenge which needs to be tackled by many actors (governments, business, scientists and individual citizens). ${ }^{5-7}$ Plastic production and usage has outgrown most other human-made materials, and with our modern lifestyles, a world without plastics is both unimaginable and impossible. When assessing the life-cycle of all plastics ever made, it is clear that the end of life fate of many plastics is currently less than ideal, ${ }^{8}$ with a notable fraction of plastic waste directly entering the environment. ${ }^{9-11}$ Microplastics, small plastic fragments $<5 \mathrm{~mm}$ in size, are currently widely considered contaminants of emerging concern in the environment, ${ }^{12,13}$ and are one of the defining indicators of the Anthropocene. ${ }^{14}$ Beyond the polymer itself, plasticizers and their metabolites have been measured in the environment for decades, ${ }^{15}$ and those which have been recognized as endocrine disruptors (bisphenol A or phthalates), have been banned or are under stringent regulation. ${ }^{16,}{ }^{17}$ Increasingly, nanoplastics has become the newest focus of the problematization of plastics in the environmental arena, ${ }^{18,19}$ but where does nanoplastics fit into the scope of global plastic pollution?

Mass media is awash with examples of plastic pollution on a global scale, the longevity of its impacts, and the difficulties associated with any potential clean-up efforts. The impact of large plastic debris in oceans has long been studied and the visual reminders of its presence are stark: biota caught in discarded fishing nets and massive "floating garbage heaps" in the gyres of the worlds' oceans. ${ }^{20}$ Reducing macroplastic litter in the environment has been the focus of environmental concern for some time, and civic engagement on this topic is an extension of the responses to tackle global environmental problems which began in the late 1960s and early 1970s. More recently, there have been further attempts to systematically transform the plastic life-cycle by reformulating products (e.g. more biodegradable options), reducing consumption (e.g. plastic bag bans and a move towards renewable alternatives), and increasing circularity (e.g. improved recycling methodologies). ${ }^{21}$ Nevertheless, a sizable fraction of the plastic waste generated year after year makes its way into the environment. The dominant fraction of particulate plastic originates from the breakdown of macroplastic litter or is released during product use (e.g. fibers from textiles or tire wear). ${ }^{22}$ The presence of microplastics has been reported in every location sampled so far: from remote mountain lakes, to arctic sea ice, ${ }^{23}$, 
${ }^{24}$ to the deep ocean floor. ${ }^{25}$ They have been found in the air we breath ${ }^{26,27}$ and the food we eat. ${ }^{28-30}$ However, due to the difficulties of current particulate plastic sampling and analysis strategies it is difficult to assess the true exposure either to humans or biota in any given location. Given the heterogeneity of both the material itself and the diversity of environments in which it resides, extrapolating the concentration, composition (i.e. chemistry) and size distribution from a few studies targeting specific environments to global occurrences of plastic particles results in considerable uncertainties. Methodological challenges and variability associated with sample collection protocol, particulate plastic extraction from different complex environmental matrices, and chemical identification continues to undermine the comparability between different studies. ${ }^{31}$

When sampling for particulate plastics, normally particles which are collected and analyzed are $10 \mu \mathrm{m}$ or larger, although a few studies have also used methods to collect and quantify smaller particles. ${ }^{32} \mathrm{~A}$ few years ago, it was hypothesized that fragmentation of plastics does not stop with microplastics, but that further fragmentation to nanosized plastics may occur. ${ }^{2,33}$ The formation of nanoplastics through weathering of plastic in laboratory-based studies provided some evidence for the formation of nanosized polymeric particles in simulated environmental situations. ${ }^{34}$ Consequently, nanoplastics may be just as widespread as other forms of plastic pollution in the environment, although it remains largely undetectable to date. ${ }^{35}$ Consequently, we are far from understanding nanoplastics exposure in most environments due to both analytical limitations in measuring nanoplastics in samples, as well as unsystematic sampling surveys across technical and environmental systems.

Furthermore, just because nanoplastics may be present in the environment, we are still uncertain of what specific hazard(s) this may pose. Recently, new experimental regimes have specifically focused on plastic exposures to begin to build a baseline to assess potential adverse effects to nanoplastics, including potential leaching of additives, amongst others. This has included specific focus on the potentially negative impacts of micro- and nanoplastics on low trophic marine fauna (see also Wright et al 2013;Alexy 2020 and Sendra et al 2021 and references therein) ${ }^{36-38}$ like the uptake of 24 and 250nm polystyrene particles in mollusks (pecten maximus) ${ }^{39}$ or $80 \mathrm{~nm}$ polystyrene induced oxidative stress in the visceral mas, gill and mantle of $C$. fluminea affecting liver functionality, neurotoxicity and intestinal inflammation (ref). This has also extended into the area of human health in relation to the accumulation of nanoplastics in the food chain, ${ }^{40}$ highlighted by the identification of nano- and microplastics in daily foodstuff such as the release from tea bags. ${ }^{29}$ as well as potential exposure via ingestion or inhalation. ${ }^{41}$ However, due to the lack of precise exposure and material data, today's hazard studies might be executed at unrealistically high concentrations or in unrealistic scenarios, with materials that may not be industrially or environmentally relevant. Consequently, it is difficult to ascertain how these exposures could relate to realistic scenarios.

\section{A nanoplastic by any other name is still a nanoplastic}

One confounding problem in assessing the risk of nanoplastics is that the term "nanoplastic" itself is still under debate, with different studies setting the upper size limit at either $100 \mathrm{~nm}$ or $1000 \mathrm{~nm}$ and no agreement on what other physical and chemical properties of nanoplastics are "realistic". This necessitates researchers who are investigating sub-micron plastic particles to discuss and elaborate on their own definition of nanoplastics in each manuscript which is published. These definitions not only include particle size or size distribution, but also origin (intentionally manufactured versus incidental versus weathering of larger plastic items), material, morphology and persistence. ${ }^{42,}{ }^{43}$ Naturally, this compounds the problem of accumulating ever increasing "niche" definitions, and ultimately makes comparability between studies even more difficult. Consequently, we do not want to add our own definition of nanoplastics into the 
mix in this current perspective, but rather address the appropriateness of using the term "nano" to describe submicron plastic particles and what connotations and implications that may have on this field of research.

The construct of a nanoplastics definition is still underway, and its utility and implications remain to be seen, but there are lessons which can be learned from previous nano-definition endeavors. In the area of engineered nanomaterials, debates on a common terminology have been ongoing for more than a decade, with arguments for and against why a definition of nanomaterials is or is not appropriate. ${ }^{44,45}$ Currently, many competing (legal) definitions continue to exist for the term "nanomaterial", including different terminology used for the European Commission and the National Nanotechnology Initiative in the U.S. This disparity between definitions is further evidenced by the nano-specific provisions adopted by the European Union for cosmetics, food and biocides which each has its own legally binding definition of the term "nanomaterial" ${ }^{46}$ Ultimately, unsolved analytical challenges make it practically impossible to classify nanomaterials according to the guidelines set out, which in turn makes the regulations (and definitions) at least partially ineffective and unenforceable.

We may not need to be so hard on ourselves just yet for not harmonizing definitions in the emerging field of nanoplastics research. Nanoscience is a domain of research built around a scale, which is among the first of its kind. In gathering ideas under the umbrella of a length scale, nanoscience has reshaped how scientists and other stakeholders understand scientific concepts, how to group information and support regulation. Some argue that there is no singular definition of nanotechnology as a whole because its breadth and complexity mean that people with different backgrounds and interests will bring their own view to the subject. ${ }^{47}$ As we have seen with the multiple and competing visions of nanotechnology, the ideas and concepts around nanoplastics may also make settling on a definition more time consuming (and problematic). Inherent to categorizing plastic debris into different size classes is the implicit suggestion that size itself is the most "important" or "connective" aspect linking the particles or the aspect of the material which is most noteworthy to study. For plastics and polymers, this may not always be the case and there are no clear scientific justifications for the size boundaries which are currently put forward. This suggests that the existing nanoplastics definitions may be more pragmatic than scientific, either in an effort to draw more clear boundaries around this new field of research or to link a nanoplastics definition to existing nanomaterial definitions. Broadly speaking, definitions are important both for regulatory purposes as well as to assist in scientific discourse. Nevertheless, when considering these aspects in the context of nanoplastics, we must ask ourselves how necessary the borders imposed by definitions are. We argue that we should look more at the continuum or discontinuum of the material itself, and what actually happens when plastic of different sizes enters the environments or interacts with organisms. At the end of the day it does not matter how you call a particle, but whether it has a specific property (e.g. toxicity, behavior) that distinguishes it.

\section{Macroplastics to nanoplastics - a true continuum? Triggers and thresholds}

Macroplastics, microplastics and nanoplastics are all related by fragmentation. Therefore, are nanoplastics just smaller microplastics? Can we speak of a continuum of plastic pieces from large items to nanoplastics, sharing common properties and effects? There are four pillars which need to be examined when addressing these questions, including 1) particle surface related properties, 2) fate and transport of particles, 3) biological interactions with particles and 4) analytical approaches to measure particles. Research on colloids and engineered nanomaterials has revealed that there are size limits and thresholds where some physicochemical processes dominate environmental behavior, which can also be examined from the viewpoint of particulate plastics (Figure 1). 
When macro- or microplastics fragment into nanoplastics, the mass of a single particle decreases but the total particle number and the total specific surface area increases. For nanotechnology, a defining feature has been that the high surface to volume ratio often imparts unique properties on a material which does not happen at other sizes. For example, there is a critical size for inorganic nanomaterials which is considerably smaller than $100 \mathrm{~nm}$, typically at approximately $20 \mathrm{~nm}$ and below, where new quantum physical based material properties appear. ${ }^{48,49}$ Particles larger than this specific size generally do not exhibit chemical or physical properties that are different from their bulk counterparts. This property is specific to metal/metal oxide-based nanomaterials due to the overlap of conduction band energy levels with the cellular redox potential, ${ }^{50}$ which does not exist in polymers. Therefore, we do not expect a similar stepwise change in properties for nanoplastics. However, processes that are related to the surface area of the particles, e.g., adsorption of other pollutants, may become more important with decreasing particle size given a certain mass of plastic. Whereas it has been shown that microplastics are not a relevant factor influencing the fate of hydrophobic organic pollutants in seawater, ${ }^{51,52}$ this might be different for nanoplastics depending on their absolute particle number and collectively higher surface area.

When plastic particles become smaller, there are a number of different processes that influence their environmental fate. Whereas polymers with a density less than $1 \mathrm{~g} / \mathrm{cm}^{3}$ float in water when they are in the micrometer range or above, there is a smaller size-range where particle behavior is determined by diffusion. In this regime, the particles become buoyant in water and floatation or sedimentation becomes less important. Larger plastic pieces can be colonized by organisms (biofouling), thereby changing their density and subsequently their fate/behavior, whereas small particles can be coated with (bio)molecules from the surrounding, defined as particle corona, or sorb to other larger particles or microorganisms (heteroaggregation). ${ }^{53,54}$ The fate of these smaller particles is then determined by the fate of the much larger heteroaggregate.$^{55}$ In porous media, e.g. soils and the subsurface, particles usually exhibit a maximum mobility at a size of approximately $1 \mu \mathrm{m}$. These size-dependent physical processes affect different size classes of plastic particles, making nanoplastics experience very different fate processes from macro- or microplastics. ${ }^{56}$ Ultimately, for fate and transport processes, different physicochemical properties dominate at different particle sizes, in other words, smaller particles can reach cells and tissues beyond biological barriers (mainly by vesicle-based transcellular transport up to $150 \mathrm{~nm})^{57}$ whereas bigger microparticles cannot so nanoplastics behavior cannot be understood based on knowledge on microplastics behavior alone.

In respect to the interactions with organisms and cells, particle size plays a crucial role. Depending on the relationship between particle size, prey size and body size, particles can be ingested and enter into the digestive tract or can be filtered from water, e.g. by gills. ${ }^{39}$ Whereas micrometer-sized particles can only be ingested by organisms which are much larger than this size, e.g. fish, ingestion of nanoplastics is also possible for microscopic organisms such as daphnids or other filter feeders. In humans, exposure might occur via inhalation, ingestion or absorption through the skin. Highly positive charged nanoparticles, including polymer-based particles, are toxic to different cell types inducing mitochondria damages or apoptosis, ${ }^{58}$ and is also reviewed as cationic toxicity. ${ }^{59}$ Inhalation is the most relevant uptake process of airborne nanomaterials for humans and therefore the most studied. Particles below $10 \mu \mathrm{m}$ (PM10) are considered to be inhalable and can reach the lungs. ${ }^{60}$ A special group of inhalable particles are those fibers that conform to the fiber paradigm (long, stiff and biopersistent fibers) and that can result into pleural mesothelioma in lungs, which is best studied for the case of asbestos. ${ }^{61}$

There is little evidence that micrometer-sized particles can cross in large amounts biological barriers such as the lung or the gut lining, and therefore these particles are largely excreted again from the body (for more detailed insights see also Wright and Kelly $)^{41}$. However, at $200-400 \mathrm{~nm}$, the biological fate of particles change: below this size, particle uptake into cells is possible ${ }^{62}$ and biological barriers, such as human term placenta, can be crossed and systemic uptake 
of particles can occur. ${ }^{63}$ Many studies on uptake and effects of several polymeric nanomaterials using different cell types have been performed to show that their uptake into cells is comparable to other nanomaterials. ${ }^{64-68}$ A good amount of knowledge about the mechanistic understanding of nanomaterial effects is available in the nanotoxicological literature from extensive studies of combustion as well as engineered nanomaterials. One major mode of action of these nanomaterials is summarized in the oxidative stress paradigm ${ }^{69} \mathrm{In}$ brief, based on the increased surface-volume ratio of nanomaterials or by the interference of the particles, the intracellular reactive oxygen species (ROS) balance can be disturbed and could create an overproduction of ROS. If not intracellularly buffered by antioxidants like vitamin $\mathrm{C}$, the radicals can oxidize cellular compounds such as proteins or lipids defined as oxidative stress. These damages further induce the expression of defense proteins and the release of (pro)-inflammatory factors. If this cell status becomes chronic, further damages may occur at the genomic level until irreversible tissue changes or tumor formation occurs. Therefore, a significant number of nanomaterial studies were performed to prove or disprove this crucial mode of action. In general, uptake of particles into cells has been observed for a wide variety of different material types, including polymers. However, there is no data proving that polymeric nanomaterials induce in a similar way then metal containing nanomaterials the formation of ROS and oxidative stress as a relevant mode of action for adverse effects.. ${ }^{49}$ Nevertheless, we may not be able to exclude that other adverse outcome pathways (AOPs) might be activated by interactions with nanoplastics. ${ }^{68}$ As with other nanomaterials, the adsorption of biomolecules onto a nanoplastics (i.e. corona formation) prior to cell or tissue interactions changes the identity of the material surface significantly and triggers different bio responses than 'naked' particles. ${ }^{54}$ Ultimately, the complexity in understanding the dynamic and complex interactions between nanoplastics and cells/organisms is hard to predict, in the sense that the combination of particle properties and exposure scenarios can make knowing precise hazards in advance challenging, but we may be able to exclude those responses which are only likely to occur when a nanomaterial has metals on its surface.

There are currently no standardized procedures to measure particulate plastic of any size in any matrix. While some activities aimed towards methodological standardization to measure particulate plastic in environmental samples are ongoing, ${ }^{70}$ most focus on microplastics opposed to nanoplastics. The microplastics analytical and conceptual toolboxes are not able to be directly applied to nanoplastics due to size or concentration limitation(s). While many of the methods developed for engineered nanomaterials may also be applicable to nanoplastics, ${ }^{71}$ the fundamental difference in material (polymer vs. metal-based) will mean that there cannot always be easy crossovers between the fields. A major challenge is that the most sensitive and specific methods for nanomaterial analysis require the analyte to be composed of metals. The analysis of carbon-based nanomaterials still suffers from serious problems at low concentrations and in complex matrices - and nanoplastics are another form of carbon-containing nanomaterial. ${ }^{72}$ On the other hand, certain analytical methods ( $\mu$ FITR or RAMAN) that are based on the chemical analysis of polymers may also not be able to identify and quantify nanoplastics since they are below the size capabilities of the instruments. In some cases, sample extraction or purification techniques may be suitable for nanoplastics, but new and different sample concentration methods would be needed in order to have the particle number/mass of nanoplastics necessary for subsequent analysis, e.g. by pyrolysis GC-MS. ${ }^{73}$ Until we are able to properly quantify the amount of nanoplastics in the environment, it will be hard to directly compare them to other forms of plastic pollution. If proper analytical methods are not developed and properly applied, we risk consistently unreliable data where nanoscientists can misinterpret the outcomes of their studies. 


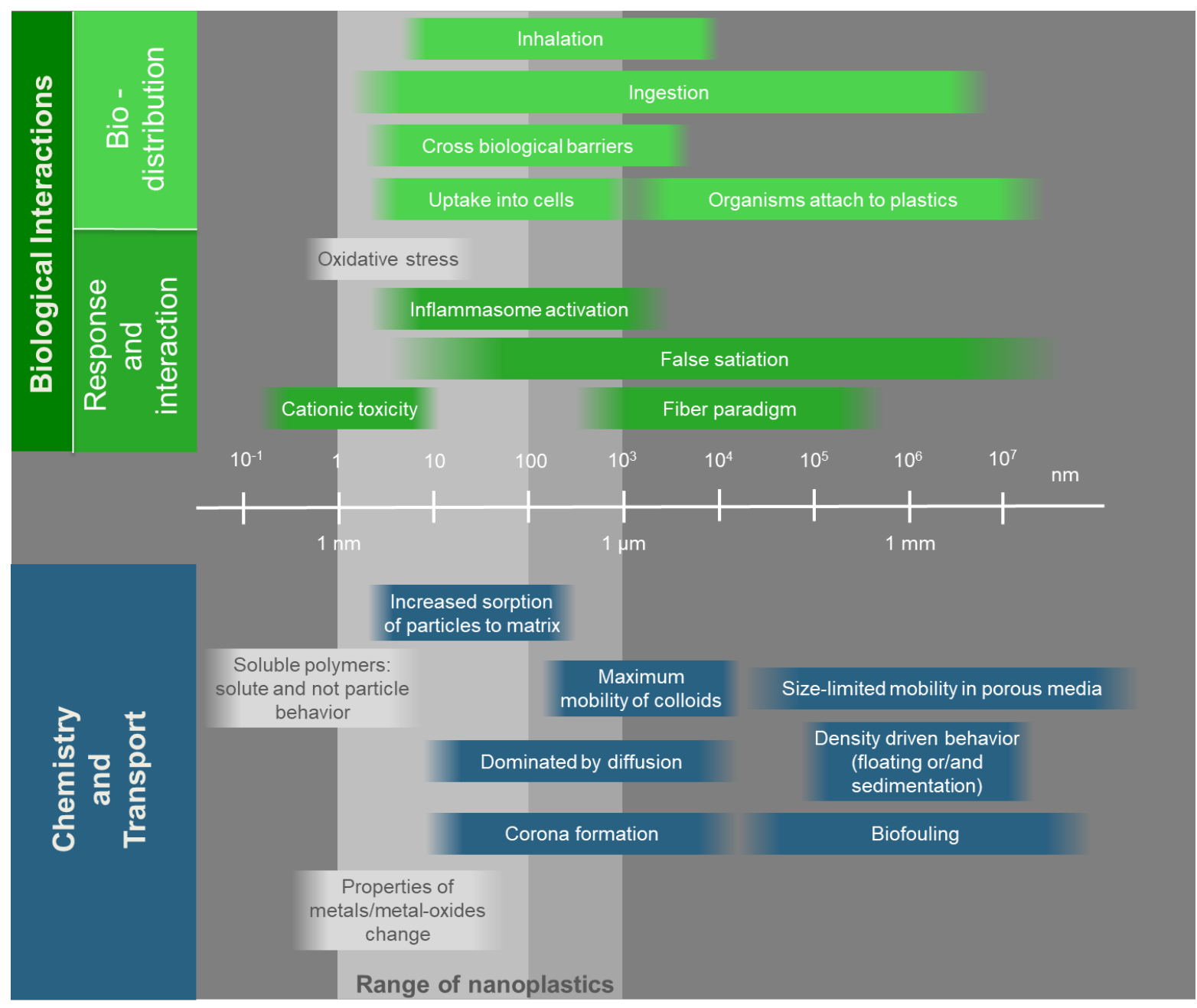

Figure 1: Changes in particle size 1) influences the physical chemistry and mobility of particles (colored blue) and 2) changes the biodistribution of particles and their responses with organisms/cells (colored green). Nano-specific properties and impacts that have so far not been observed for nanoplastics but have been observed for metalcontaining nanomaterials are colored grey. The vertical grey bands denote the size range(s) covered by the various definitions of nanoplastics (1- $100 \mathrm{~nm}$, light grey; definition extension to $1000 \mathrm{~nm}$, dark grey). Note that not all relevant processes and impacts of particles are shown in the figure, but this is meant to highlight those which with authors find prevalent in the field.

\section{Nanoplastics are not alone - there are many other particles in the environment}

Nanoplastics are not the only particles present in the environment - particles are an important and crucial component of any natural system: in air, water, sediment and soils. Natural nanomaterials far outnumber engineered nanomaterials in the environment, ${ }^{74,75}$ and these natural nanomaterials are present together with anthropogenic particles (Figure 2). A wide variety of natural and anthropogenic materials exist in the size range defined by ISO as the "nano-range" (grey shading, Figure 2) ${ }^{76}$ Natural nanomaterials can be organic as well as inorganic and can have biogenic or geogenic origins. ${ }^{77}$ Examples of natural nanomaterials are polysaccharides excreted from plants or microorganisms and fulvic and humic acids that are formed during the degradation of organic matter. Inorganic nanomaterials such as iron- or manganese-oxides, clays and silicates, can have either geogenic or biogenic origins. 
In addition to natural particles, a suite of anthropogenic materials is present in the environment extending down to the nano-size range. Some of these materials are unintentionally formed, e.g., combustion-generated particles or those produced by abrasion processes. Abrasion can occur during high-energy processes such as drilling or sanding, but also by natural processes such as weathering. These particles can be organic as well as inorganic and many are formed by traffic-related processes, e.g. during combustion or by road- and tire-wear. The size range of many pigments also partially fall into the nano-range, ${ }^{78}$ although they are engineered to have average sizes of a few hundred nanometers. A group of particles intentionally designed to be in the nano-range are engineered (also called manufactured) nanomaterials. ${ }^{79}$ These particles have various compositions and uses and are predicted to be released by various processes during production, use and disposal. ${ }^{80}$ Significant progress has been made in the last years to develop analytical methods to quantify some of these materials, mainly those containing metals, at environmentally relevant concentrations in natural samples. These efforts have shown that isolating and quantifying engineered nanomaterials in complex environmental matrices suffers from the problem that one needs to "find the needle in the haystack". Often present in small concentrations, engineered particles are difficult to identify and distinguish amongst an overwhelming number of natural particles, some of them with the same or very similar composition. ${ }^{81}$

Within this mix of natural and anthropogenic particles, nanoplastics constitute another component and contribute to the total particulate content in natural systems. Whereas a wealth of studies exist on microplastic detection in air, freshwaters and marine systems, ${ }^{82-84}$ and therefore we have at least some estimates on their amounts in the environment, the concentrations of nanoplastics in the environment are not yet known. Thus, their contribution to the total (nano-sized) particle number and mass in the environment remains unclear. However, given the absence of any quantitative information on their occurrence, it is prudent to invest in the study of nanoplastics, especially given the enormous size of the plastic reservoir on Earth that could potentially form nanoplastics. Realistically, one could assume that a portion of the macro- and microplastics will eventually fragment into nanoplastics, which consequently would equate to very high particle numbers. Nevertheless, given the magnitude of the natural nanomaterial pool, it is likely that nanoplastics will not significantly change the total mass balance of the nanoparticulate mass on earth. ${ }^{74}$ 


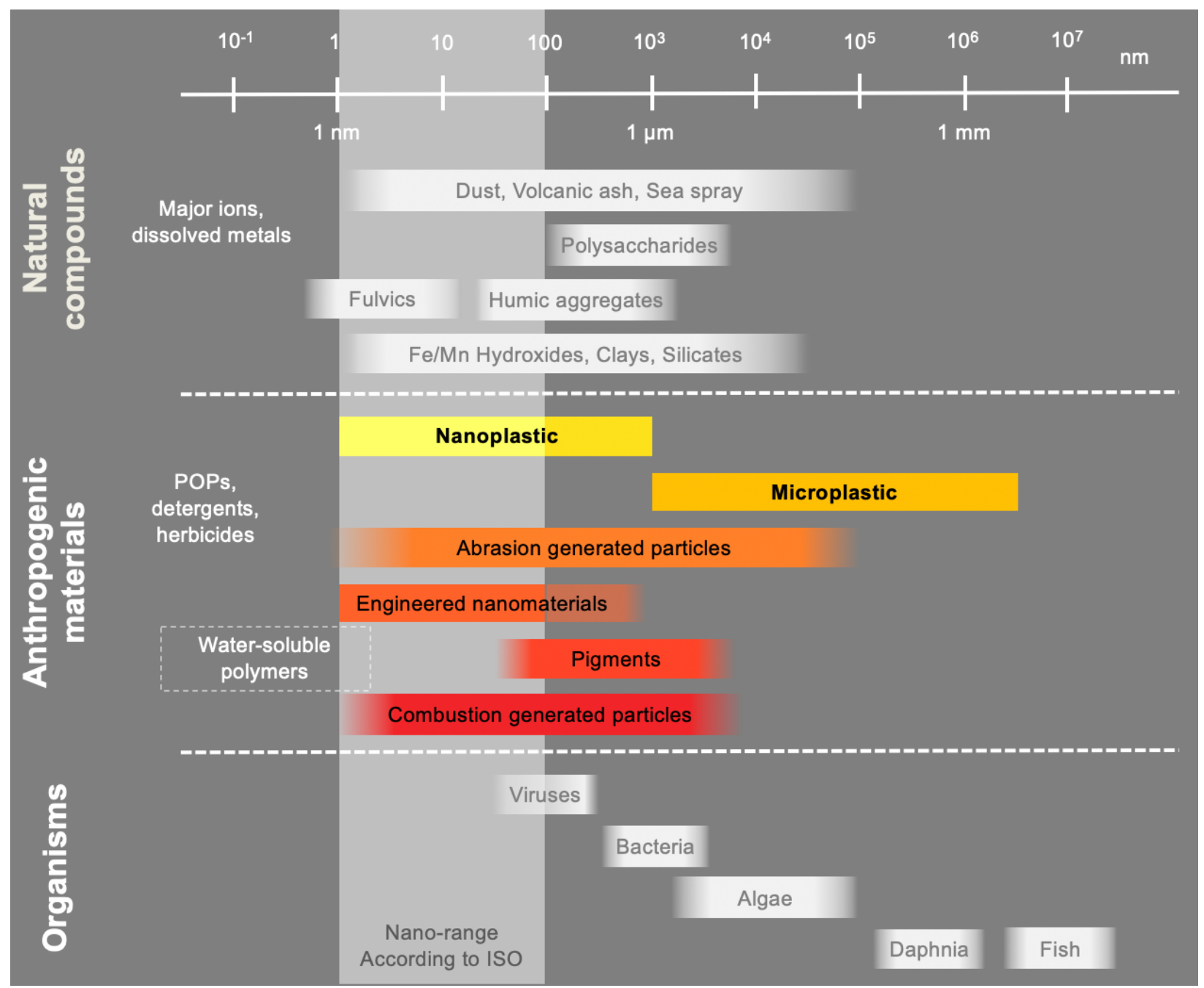

Figure 2: Approximate sizes of natural and anthropogenic particles and compounds in the environment. The grey shaded area denotes the nano-size according to the ISO definition. Anthropogenic particles are shown in colored bars.

There are continuous changes of the material properties of plastic over the whole size spectrum - not one particular nano-property which can be seen - and so it's difficult to say exactly when and where the nano-size fraction of plastics would have something unique. Important and impactful changes and consequences could also happen at other/different sizes (both larger and smaller). As shown in Figure 1, nanoplastics should not only be seen as an "extension" of the macroplastic and microplastic problems, but rather as a size-class of materials which in some instances have different properties and bio-responses than larger particles of the same polymers even if they share the same chemical identity. Nevertheless, strict definitions and size classifications for particulate plastics may be counter-productive in collectively understanding impacts of (particulate) plastic in the environment. As shown in Figure 1, there is a continuum of changes over the whole size range that may or may not conform to a specific definition. For plastics, there is not always a clear scientific justification for the size boundaries which are currently used in either the microplastic or the (various) nanoplastics definitions. Unlike in the case of engineered nanomaterials, size is likely not directly related to unique material properties but rather is a function of how the material behaves in the environment, interacts with organisms, or is measured and characterized. 


\section{Viewpoints influencing nanoplastics perception}

The topic nanoplastics can be seen through different lenses and can influence the current debate in a multifaceted way. How engineered nanomaterials were initially portrayed in the media may give some indication as to how nanoplastics may also be perceived in the coming years. 'Nanoparticles cause brain damage', or 'increased cancer risk by titanium dioxide in toothpaste' are two examples of headlines circulating in the news after scientific studies on engineered nanoparticles were published, in these cases by Oberdörster et al. in 2004 on fullerenes or Tschopp and coworkers in 2010 on titanium dioxide, respectively. ${ }^{85,86}$ These headlines were designed to attract as much attention as possible on the topic of nanomaterials on an emotional level. By presenting information in this way, the term "nano" was not only burned in the readers' mind but potentially made a long-lasting negative connotation with the prefix nano. In combination with todays' headlines on plastic littering, its effects on wildlife and an increasing number of press releases of microplastic studies, both nano and plastic may be picked up as a dire new emerging environmental problem despite the lack of quantitative and evidence-based knowledge on their impacts. Take for example the World Economic Forum with its 2018 headline "Microplastic and nanoplastic pollution threatens our environment. How should we respond?" ${ }^{87}$ As for any topic which relies on these 'gut-feelings' to promote awareness, it is evident that if the topic reaches a certain recognition, researchers and funding agencies will (correctly) become active to try to provide a more scientific and evidence-based views on the topic. As research on the environmental health and safety of engineered nanomaterials begins to wane, this is an opportunity for many researchers to study similar topics under the guise of a new material. However, we believe that the relationship with the term "nano", from both perception and environmental standpoints, does differentiate itself from other anthropogenic materials. There is a mutual influence between media and academia in the hunt for attention and citations, as both profit from each other, an issue of currently much higher relevance for microplastic research. ${ }^{88}$

Whereas most of the engineered nanomaterials pass through wastewater treatment plants or other technical system where they are efficiently removed, ${ }^{89}$ nanoplastics have the potential to be formed directly in the environment from degradation of microplastics and thus these particles may be even more widespread and omnipresent than engineered nanomaterials. In the eyes of many, this may make them even scarier than other nano-contaminants with a more pressing need to understand the consequences of them being in the environment. These perceptions may not be completely unfounded, as many particulate pollutants are indeed problematic. There are many facets which contribute to the perception of how individuals may look at nanoplastics, and depending on which lens one is looking through, polymer particles in the nano-size range may have positive or negative connotations (Figure 3). For those who work in the field of nanomedicine, the use of polymers may be favorably viewed as a safe opportunity for novel and impactful solutions like drug delivery. These materials usually have very low human- and ecotoxicity, ${ }^{90,91}$ indicating that polymeric particles with a small size do not necessarily cause adverse effects. To provide an efficient and safe use of polymers, mostly used in the nano to submicron size range, in medicine the material quality plays a crucial rule. Therefore, the material- and biomedical characterization of nanomedicines are well-developed and provide important analytical and biomedical knowledge to today's debate and challenges in nanoplastics research. Conversely, the health effects caused by different types of particles are a well-known and are a serious problem worldwide. Inhalation of certain mineral dusts can cause silicosis or asbestosis, which is still fresh in the minds of people as buildings continue to be refurbished to remove dangerous building materials. These examples may give an underlying notion that particles are inherently problematic to human health. However, there is also a range of viewpoints which nanoplastics can be perceived which lie between these two extremes (Figure 3). When we look at the most toxic engineered nanomaterials, such as those composed of metals with known dissolved ion toxicity or fibrous nanomaterials, there may indeed be cause for concern. However, engineered nanomaterials consist of many different subclasses of materials and one cannot take properties of one class and extrapolate them to a different class of nanomaterials. We should avoid 
scientifically unsound shortcuts for comparing particles of different physical chemistry, origin and utility which just happen to have the same (nano) size. In many cases, the only connecting factor is the length scale of the material, and thus the environmental and health impacts may not be similar. The fact that nano-silver has a high toxicity towards bacteria and other microorganisms is no reason to assume that nanoplastics will share commonalities with this particle. ${ }^{92}$ Furthermore, nano- $\mathrm{TiO}_{2}$, with its photocatalytic activity, or many metal(oxide)-nanomaterials with high redox activity, are bad proxies to make predictions about nanoplastics hazards. These aspects are not exhaustive and readers of this perspective may identify other viewpoints influencing nanoplastics perceptions underlining the multilayered facets of the current perception and debate of nanoplastics we have today.

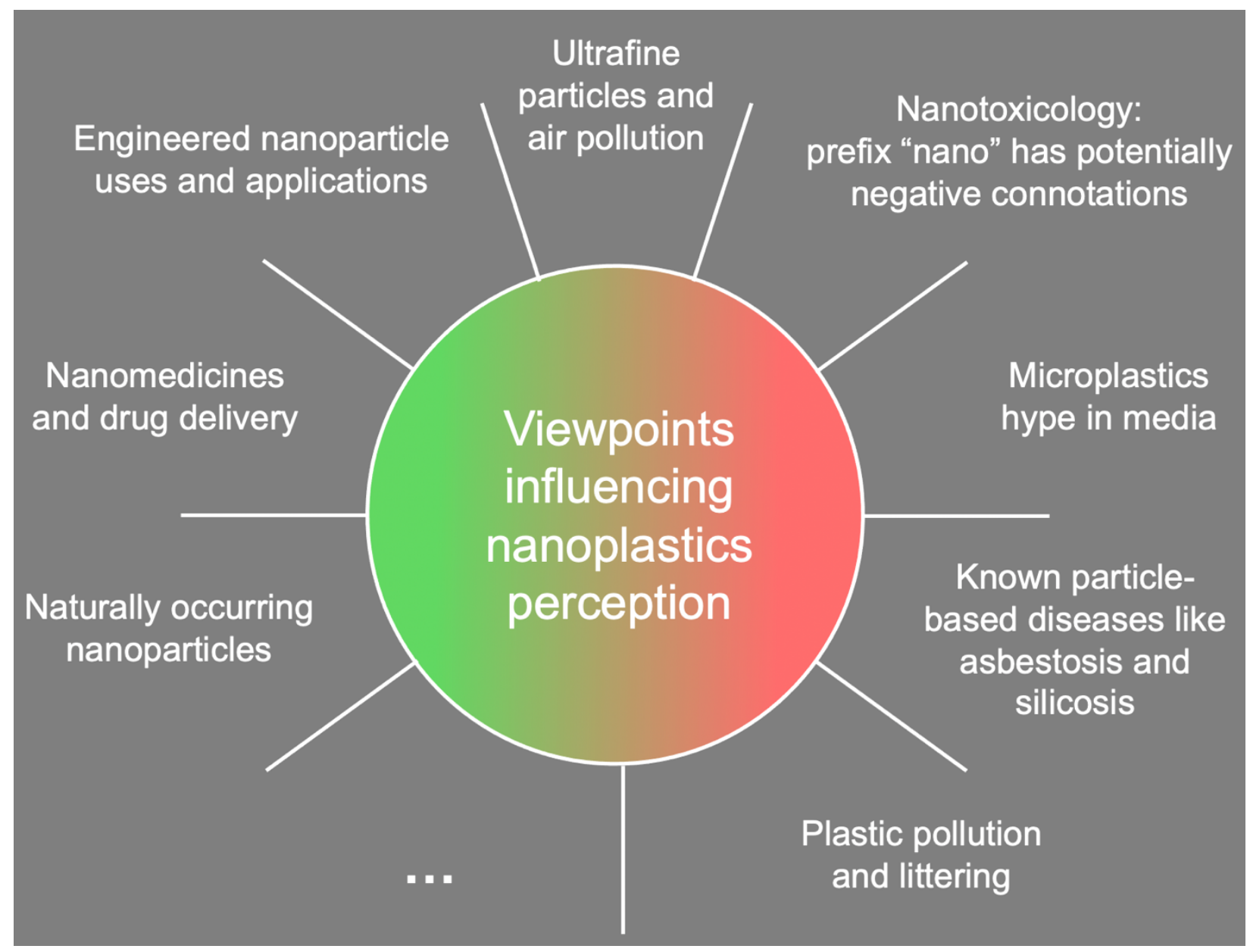

Figure 3: The differing viewpoints that influence nanoplastics perceptions underline multilayered facets surrounding the issues of plastic use, pollution, and putting it in place with other environmental nanomaterials and diseases. . Polymeric nano-sized particles can be viewed through different lenses, and depending on which lens one is looking through, nanoplastics may be have positive (green) or negative (red) connotations. The lenses through which to view nanoplastics listed here is not exhaustive and readers of this perspective may also identify other facets that may contribute to nanoplastics perception.

Towards assessing risks of nanoplastics - a responsible approach from environmental nanoscientists 
Environmental science is an applied and multidisciplinary research field. However, emerging contaminants have become a fashionable and trendy research area, which may or may not relate back to "the real world". The hype surrounding engineered nanotechnologies between 2005 and 2015 has slowly faded, and the presence of engineered nanomaterials in consumer products has become more accepted and commonplace. For scientists, too, changes have continued to take place in the ways we look at possible environmental and health effects of nanomaterials as highlighted by Maynard and Aikten. ${ }^{93}$ While at present there is still no complete understanding of toxicity mechanisms of nanomaterials (i.e. no "read across toxicity or predictive toxicology"), ${ }^{94,95}$ the physicochemical features of a given nanomaterial and their subsequent effects on particle toxicity are still in focus. Therefore, extensive characterization of nanomaterials has become more important to better relate particle specific characteristics to safety and risk assessment, and to develop research priorities and testing strategies. ${ }^{96}$ More and more, the understanding from colloidal science that nanomaterials are an integral part of environmental systems makes its way into the discussion about particles of anthropogenic origin. This is particularly highlighted in the fact that despite all the advances in analytical methods to characterize engineered nanomaterials, it is often still a struggle to distinguish engineered nanomaterials from their natural counterparts.

For prioritizing needs for action, nanoplastics research should focus on identifying the possible magnitude of potential exposure and hazards. Ultimately, support for environmental research should favor studies which stimulate timely decision-making and prudent actions to prevent hazard - not abstract iterations which do not represent realistic exposure scenarios. In this regard, the lessons learned from engineered nanomaterials may be drawn upon as we now develop workflows to assess nanoplastics. ${ }^{97,98}$ To facilitate the safe and sustainable use of nanomaterials, a suite of frameworks and tools to assess their risks were developed in the last years. ${ }^{99-101}$ Whereas many of these tools are only able to provide screening-level assessments, there are ongoing activities to develop quantitative, higher-tier tools that can also incorporate uncertainty during the evaluation process. Several learnings, warnings and potential working hypothesis from the field of engineered nanomaterial environmental health and safety, ${ }^{40,97}$ as well as recommendations for minimal information reporting in the bio-nano experimental field, ${ }^{102}$ are published and will hopefully steer and accelerate nanoplastics research and provide profound understanding on the concentration, fate and environmental health and safety of nanoplastics soon.

As data accumulates on the environmental chemistry, ecotoxicological and human toxicity as well as the epidemiology of nanoplastics, this may ultimately conclude with government action to establish environmental guidelines or criteria to ensure adequate protection. However, for nanoplastics, this may prove especially difficult as the main environmental source of nanoplastics is mismanaged macroplastic waste or unintentionally released microplastics, and thus targeting nanoplastics specifically is largely impossible. While environmental nanoplastics are just pollutants without any benefits, engineered nanomaterials have a specific function in products and have clear benefits to consumers. From this point of view, the presence of low concentrations of engineered nanomaterials in the environment may be more "acceptable" than nanoplastics. It is well known from risk perception research that in situations with little knowledge and where a person has no control over the risk, the acceptability of risk is much lower than in situations with known high risks but with full (perceived) control. ${ }^{103}$ In this context, the scientific community who is now studying nanoplastics can learn from phrasing used to portray microplastic risks. ${ }^{104-106}$ This debate centers around the communication of the probability of risk of microplastic to human health in the absence of clear evidence but with data that suggest that there is little risk given the current knowledge. As nanoscientists specializing in understanding the fate, transport and interactions of nanoparticles in human and environmental systems, how can we learn from this to frame our research in a way which is most digestible by our colleagues, regulators and the public?

\section{Outlook}


Nanoplastics are currently considered a contaminant of emerging concern, since there is little clarity on the true magnitude of nanoplastics pollution and there is not enough data in the scientific literature to conduct a proper risk assessment. This lack of pertinent information concerning the environmental fate and ecotoxicological impacts prevent a proper evaluation of nanoplastics at the moment, and thus the continued study of nanoplastics is certainly warranted. However, we must keep in mind that not all contaminants of emerging concern will actually prove to have as dramatically negative impacts as was initially attributed to them. As scientists, we have to focus our attention on providing hard data to understand the impacts these materials could have in the real world and suggest options to mitigate risks. In the case of nanoplastics, this is more complicated: even if/when nanoplastics were found to cause adverse effects, the solutions are likely not to focus on targeting nanoplastics themselves for regulation, but rather other aspects of plastic design, use and waste management strategies. Green chemistry, solid waste management and circular economy are their own fields of study, and together with regulatory action, can be optimized to reduce the burden of plastics in the environment. As environmental scientists working on the impacts of nanoplastics, we can underscore the necessity of improving the plastic life-cycle by fully elucidating the depth and breadth of adverse outcomes the plastic pollution crisis, all the way down to the nano-scale.

\section{Acknowledgements}

D.M.M was supported through the Swiss National Science Foundation, grant number PCEFP2_186856.

\section{Competing Interests}

The authors declare no competing interests.

\section{References}

1. Boucher, J.; Friot, D., Primary microplastics in the oceans: a global evaluation of sources. IUCN Gland, Switzerland: 2017.

2. Lambert, S.; Wagner, M., Characterisation of nanoplastics during the degradation of polystyrene. Chemosphere 2016, 145, 265-268.

3. $\quad$ El Hadri, H.; Gigault, J.; Maxit, B.; Grassl, B.; Reynaud, S., Nanoplastic from mechanically degraded primary and secondary microplastics for environmental assessments. NanoImpact 2020, 17, 100206.

4. Sauvé, S.; Desrosiers, M., A review of what is an emerging contaminant. Chemistry Central Journal 2014, $8,(1), 1-7$.

5. Haward, M., Plastic pollution of the world's seas and oceans as a contemporary challenge in ocean governance. Nature communications 2018, 9, (1), 667.

6. Landon-Lane, M., Corporate social responsibility in marine plastic debris governance. Marine pollution bulletin 2018, 127, 310-319.

7. Loges, B.; Jakobi, A. P., Not more than the sum of its parts: de-centered norm dynamics and the governance of plastics. Environmental Politics 2019, 1-20.

8. $\quad$ Lau, W. W.; Shiran, Y.; Bailey, R. M.; Cook, E.; Stuchtey, M. R.; Koskella, J.; Velis, C. A.; Godfrey, L.; Boucher, J.; Murphy, M. B., Evaluating scenarios toward zero plastic pollution. Science 2020.

9. Geyer, R.; Jambeck, J. R.; Law, K. L., Production, use, and fate of all plastics ever made. Science Advances 2017, 3, (7), e1700782.

10. $\quad$ Ryberg, M. W.; Hauschild, M. Z.; Wang, F.; Averous-Monnery, S.; Laurent, A., Global environmental losses of plastics across their value chains. Resources, Conservation and Recycling 2019, 151, 104459.

11. Boucher, J.; Dubois, C.; Kounina, A.; Puydarrieux, P. Review of plastic footprint methodologies; 2831719909; IUCN: 2019.

12. Lambert, S.; Wagner, M., Microplastics are contaminants of emerging concern in freshwater environments: an overview. In Freshwater microplastics, Springer, Cham: 2018; pp 1-23. 
13. Lambert, S.; Wagner, M., Environmental performance of bio-based and biodegradable plastics: the road ahead. Chemical Society Reviews 2017, 46, (22), 6855-6871.

14. Waters, C. N.; Zalasiewicz, J.; Summerhayes, C.; Barnosky, A. D.; Poirier, C.; Gałuszka, A.; Cearreta, A.; Edgeworth, M.; Ellis, E. C.; Ellis, M., The Anthropocene is functionally and stratigraphically distinct from the Holocene. Science 2016, 351, (6269), aad2622.

15. Horn, O.; Nalli, S.; Cooper, D.; Nicell, J., Plasticizer metabolites in the environment. Water Research 2004, 38, (17), 3693-3698.

16. Erler, C.; Novak, J., Bisphenol a exposure: human risk and health policy. Journal of pediatric nursing 2010, 25, (5), 400-407.

17. Wazir, U.; Mokbel, K., Bisphenol A: A Concise Review of Literature and a Discussion of Health and Regulatory Implications. in vivo 2019, 33, (5), 1421-1423.

18. Dauvergne, P., The power of environmental norms: marine plastic pollution and the politics of microbeads. Environmental Politics 2018, 27, (4), 579-597.

19. Mitrano, D. M.; Wohlleben, W., Microplastic regulation should be more precise to incentivize both innovation and environmental safety. Nature communications 2020, 11, (1), 1-12.

20. Eriksen, M.; Lebreton, L. C.; Carson, H. S.; Thiel, M.; Moore, C. J.; Borerro, J. C.; Galgani, F.; Ryan, P. G.; Reisser, J., Plastic pollution in the world's oceans: more than 5 trillion plastic pieces weighing over 250,000 tons afloat at sea. PloS one 2014, 9, (12), e111913.

21. Simon, B., What are the most significant aspects of supporting the circular economy in the plastic industry? resources, Conservation and Recycling 2019, 141, 299-300.

22. GESAMP Sources, fate and effects of microplastics in the marine environment: a global assessment; Joint group of experts on the scientific aspects of marine environmental protection: 2015.

23. Lusher, A. L.; Tirelli, V.; O'Connor, I.; Officer, R., Microplastics in Arctic polar waters: the first reported values of particles in surface and sub-surface samples. Scientific reports 2015, 5, 14947.

24. Bergmann, M.; Mützel, S.; Primpke, S.; Tekman, M. B.; Trachsel, J.; Gerdts, G., White and wonderful? Microplastics prevail in snow from the Alps to the Arctic. Science advances 2019, 5, (8), eaax1157.

25. Bergmann, M.; Wirzberger, V.; Krumpen, T.; Lorenz, C.; Primpke, S.; Tekman, M. B.; Gerdts, G., High quantities of microplastic in Arctic deep-sea sediments from the HAUSGARTEN observatory. Environmental science \& technology 2017, 51, (19), 11000-11010.

26. Vianello, A.; Jensen, R. L.; Liu, L.; Vollertsen, J., Simulating human exposure to indoor airborne microplastics using a Breathing Thermal Manikin. Scientific reports 2019, 9, (1), 1-11.

27. Zhang, Q.; Zhao, Y.; Du, F.; Cai, H.; Wang, G.; Shi, H., Microplastic Fallout in Different Indoor Environments. Environmental Science \& Technology 2020.

28. Shruti, V.; Peréz-Guevara, F.; Elizalde-Martínez, I.; Kutralam-Muniasamy, G., First study of its kind on the microplastic contamination of soft drinks, cold tea and energy drinks-Future research and environmental considerations. Science of The Total Environment 2020, 138580.

29. Hernandez, L. M.; Xu, E. G.; Larsson, H. C.; Tahara, R.; Maisuria, V. B.; Tufenkji, N., Plastic teabags release billions of microparticles and nanoparticles into tea. Environmental science \& technology 2019, 53, (21), 12300-12310.

30. Cox, K. D.; Covernton, G. A.; Davies, H. L.; Dower, J. F.; Juanes, F.; Dudas, S. E., Human consumption of microplastics. Environmental science \& technology 2019, 53, (12), 7068-7074.

31. Provencher, J. F.; Covernton, G. A.; Moore, R. C.; Horn, D. A.; Conkle, J. L.; Lusher, A. L., Proceed with caution: The need to raise the publication bar for microplastics research. Science of The Total Environment 2020, 141426.

32. Mintenig, S. M.; Bauerlein, P.; Koelmans, A. A.; Dekker, S. C.; van Wezel, A., Closing the gap between small and smaller: Towards a framework to analyse nano-and microplastics in aqueous environmental samples. Environmental Science: Nano 2018, 5, 1640-1649.

33. Gigault, J.; Pedrono, B.; Maxit, B.; Ter Halle, A., Marine plastic litter: the unanalyzed nano-fraction. Environmental Science: Nano 2016, 3, (2), 346-350.

34. González-Pleiter, M.; Tamayo-Belda, M.; Pulido-Reyes, G.; Amariei, G.; Leganés, F.; Rosal, R.; Fernández-Piñas, F., Secondary nanoplastics released from a biodegradable microplastic severely impact freshwater environments. Environmental Science: Nano 2019, 6, (5), 1382-1392.

35. Koelmans, A. A.; Besseling, E.; Shim, W. J., Nanoplastics in the aquatic environment. Critical review. In Marine anthropogenic litter, Springer: 2015; pp 325-340.

36. Wright, S. L.; Thompson, R. C.; Galloway, T. S., The physical impacts of microplastics on marine organisms: a review. Environmental Pollution 2013, 178, 483-492. 
37. Alexy, P.; Anklam, E.; Emans, T.; Furfari, A.; Galgani, F.; Hanke, G.; Koelmans, A.; Pant, R.; Saveyn, H.; Sokull Kluettgen, B., Managing the analytical challenges related to micro-and nanoplastics in the environment and food: filling the knowledge gaps. Food Additives \& Contaminants: Part A 2020, 37, (1), 1-10.

38. Sendra, M.; Sparaventi, E.; Novoa, B.; Figueras, A., An overview of the internalization and effects of microplastics and nanoplastics as pollutants of emerging concern in bivalves. Science of The Total Environment 2020, 142024.

39. Al-Sid-Cheikh, M.; Rowland, S. J.; Stevenson, K.; Rouleau, C.; Henry, T. B.; Thompson, R. C., Uptake, Whole-body distribution, and depuration of nanoplastics by the scallop pecten maximus at environmentally realistic concentrations. Environmental science \& technology 2018, 52, (24), 14480-14486.

40. Bouwmeester, H.; Hollman, P. C.; Peters, R. J., Potential health impact of environmentally released microand nanoplastics in the human food production chain: experiences from nanotoxicology. Environmental science \& technology 2015, 49, (15), 8932-8947.

41. Wright, S. L.; Kelly, F. J., Plastic and human health: a micro issue? Environmental science \& technology 2017, 51, (12), 6634-6647.

42. $\quad$ Hartmann, N. B.; Hüffer, T.; Thompson, R. C.; Hassellöv, M.; Verschoor, A.; Daugaard, A. E.; Rist, S.; Karlsson, T.; Brennholt, N.; Cole, M., Are we speaking the same language? Recommendations for a definition and categorization framework for plastic debris. In ACS Publications: 2019.

43. $\quad$ Gigault, J.; Ter Halle, A.; Baudrimont, M.; Pascal, P.-Y.; Gauffre, F.; Phi, T.-L.; El Hadri, H.; Grassl, B.; Reynaud, S., Current opinion: What is a nanoplastic? Environmental Pollution 2018, 235, 1030-1034.

44. $\quad$ Maynard, A. D., Don't define nanomaterials. Nature 2011, 475, (7354), 31-31.

45. Stamm, H., Nanomaterials should be defined. Nature 2011, 476, (7361), 399-399.

46. Miernicki, M.; Hofmann, T.; Eisenberger, I.; von der Kammer, F.; Praetorius, A., Legal and practical challenges in classifying nanomaterials according to regulatory definitions. Nature nanotechnology 2019, 14, (3), 208-216.

47. Toumey, C., The philosopher and the engineer. Nature nanotechnology 2016, 11, (4), 306-307.

48. Auffan, M.; Rose, J.; Bottero, J.; Lowry, G.; Jolivet, J.; Wiesner, M., Towards a definition of inorganic nanoparticles from an environmental, health and safety perspective. Nature Nanotechnology 2009, 4, (10), 634-641. 49. Zhang, H.; Ji, Z.; Xia, T.; Meng, H.; Low-Kam, C.; Liu, R.; Pokhrel, S.; Lin, S.; Wang, X.; Liao, Y.-P., Use of metal oxide nanoparticle band gap to develop a predictive paradigm for oxidative stress and acute pulmonary inflammation. ACS nano 2012, 6, (5), 4349-4368.

50. Burello, E.; Worth, A. P., A theoretical framework for predicting the oxidative stress potential of oxide nanoparticles. Nanotoxicology 2011, 5, (2), 228-235.

51. Koelmans, A. A.; Bakir, A.; Burton, G. A.; Janssen, C. R., Microplastic as a vector for chemicals in the aquatic environment: critical review and model-supported reinterpretation of empirical studies. Environmental science \& technology 2016, 50, (7), 3315-3326.

52. Lohmann, R., Microplastics are not important for the cycling and bioaccumulation of organic pollutants in the oceans - but should microplastics be considered POPs themselves? Integrated environmental assessment and management 2017, 13, (3), 460-465.

53. Cedervall, T.; Lynch, I.; Lindman, S.; Berggård, T.; Thulin, E.; Nilsson, H.; Dawson, K. A.; Linse, S., Understanding the nanoparticle-protein corona using methods to quantify exchange rates and affinities of proteins for nanoparticles. Proceedings of the National Academy of Sciences 2007, 104, (7), 2050-2055.

54. $\quad$ Docter, D.; Westmeier, D.; Markiewicz, M.; Stolte, S.; Knauer, S.; Stauber, R., The nanoparticle biomolecule corona: lessons learned-challenge accepted? Chemical Society Reviews 2015, 44, (17), 6094-6121.

55. Frehland, S.; Kägi, R.; Hufenus, R.; Mitrano, D. M., Understanding the fate of nanoplastic particles and microplastic fibers through wastewater treatment: mass balance across a pilot plant using metal-doped plastics.

\section{Under Review.}

56. Keller, A. S.; Jimenez-Martinez, J.; Mitrano, D. M., Transport of nano-and microplastic through unsaturated porous media from sewage sludge application. Environmental Science \& Technology 2019.

57. Mayor, S.; Pagano, R. E., Pathways of clathrin-independent endocytosis. Nature reviews Molecular cell biology 2007, 8, (8), 603-612.

58. McNeil, S. E., Nanoparticle therapeutics: a personal perspective. Wiley Interdisciplinary Reviews: Nanomedicine and Nanobiotechnology 2009, 1, (3), 264-271.

59. Wang, F.; Bexiga, M. G.; Anguissola, S.; Boya, P.; Simpson, J. C.; Salvati, A.; Dawson, K. A., Time resolved study of cell death mechanisms induced by amine-modified polystyrene nanoparticles. Nanoscale 2013, 5, (22), 10868-10876. 
60. Geiser, M.; Kreyling, W. G., Deposition and biokinetics of inhaled nanoparticles. Particle and fibre toxicology 2010, 7, (1), 1-17.

61. Donaldson, K.; Murphy, F. A.; Duffin, R.; Poland, C. A., Asbestos, carbon nanotubes and the pleural mesothelium: a review of the hypothesis regarding the role of long fibre retention in the parietal pleura, inflammation and mesothelioma. Particle and fibre toxicology 2010, 7, (1), 5.

62. Geiser, M.; Rothen-Rutishauser, B.; Kapp, N.; Schürch, S.; Kreyling, W.; Schulz, H.; Semmler, M.; Hof, V. I.; Heyder, J.; Gehr, P., Ultrafine particles cross cellular membranes by nonphagocytic mechanisms in lungs and in cultured cells. Environmental health perspectives 2005, 113, (11), 1555-1560.

63. Wick, P.; Malek, A.; Manser, P.; Meili, D.; Maeder-Althaus, X.; Diener, L.; Diener, P.-A.; Zisch, A.; Krug, H. F.; von Mandach, U., Barrier capacity of human placenta for nanosized materials. Environmental health perspectives 2010, 118, (3), 432-436.

64. Mastrangelo, G.; Fedeli, U.; Fadda, E.; Milan, G.; Turato, A.; Pavanello, S., Lung cancer risk in workers exposed to poly (vinyl chloride) dust: a nested case-referent study. Occupational and environmental medicine 2003, $60,(6), 423-428$.

65. Rothen-Rutishauser, B.; Blank, F.; Mühlfeld, C.; Gehr, P., In vitro models of the human epithelial airway barrier to study the toxic potential of particulate matter. Expert opinion on drug metabolism \& toxicology 2008, 4, (8), 1075-1089.

66. Borm, P. J.; Kreyling, W., Toxicological hazards of inhaled nanoparticles - potential implications for drug delivery. Journal of nanoscience and nanotechnology 2004, 4, (5), 521-531.

67. Hesler, M.; Aengenheister, L.; Ellinger, B.; Drexel, R.; Straskraba, S.; Jost, C.; Wagner, S.; Meier, F.; von Briesen, H.; Büchel, C., Multi-endpoint toxicological assessment of polystyrene nano-and microparticles in different biological models in vitro. Toxicology in Vitro 2019, 61, 104610.

68. Lehner, R.; Weder, C.; Petri-Fink, A.; Rothen-Rutishauser, B., Emergence of nanoplastic in the environment and possible impact on human health. Environmental science \& technology 2019, 53, (4), 1748-1765. 69. Donaldson, K.; Stone, V.; Tran, C.; Kreyling, W.; Borm, P. J., Nanotoxicology. In BMJ Publishing Group Ltd: 2004.

70. $\quad$ Nguyen, B.; Claveau-Mallet, D.; Hernandez, L. M.; Xu, E. G.; Farner, J. M.; Tufenkji, N., Separation and analysis of microplastics and nanoplastics in complex environmental samples. Accounts of chemical research 2019, $52,(4), 858-866$.

71. Hüffer, T.; Praetorius, A.; Wagner, S.; von der Kammer, F.; Hofmann, T., Microplastic exposure assessment in aquatic environments: learning from similarities and differences to engineered nanoparticles. In ACS Publications: 2017.

72. Zhang, M.; Yang, J.; Cai, Z.; Feng, Y.; Wang, Y.; Zhang, D.; Pan, X., Detection of engineered nanoparticles in aquatic environments: current status and challenges in enrichment, separation, and analysis. Environmental Science: Nano 2019, 6, (3), 709-735.

73. Hildebrandt, L.; Mitrano, D. M.; Zimmermann, T.; Pröfrock, D., A Nanoplastic Sampling and Enrichment Approach by Continuous Flow Centrifugation. Frontiers in Environmental Science 2020.

74. Hochella, M. F.; Mogk, D. W.; Ranville, J.; Allen, I. C.; Luther, G. W.; Marr, L. C.; McGrail, B. P.; Murayama, M.; Qafoku, N. P.; Rosso, K. M., Natural, incidental, and engineered nanomaterials and their impacts on the Earth system. Science 2019, 363, (6434).

75. Hochell, M. F.; Aruguete, D. M.; Kim, B.; Madden, A. S., Naturally occurring inorganic nano particles: General assessment and a global budget for one of earth's last unexplored major geochemical components. In Nature's Nanostructures, Pan Stanford Publishing Pte. Ltd.: 2012; pp 1-42.

76. Nanotechnologies-Terminology, I., definitions for nano-objects-Nanoparticle, nanofibre and nanoplate. International Organization for Standardization 2008.

77. Buffle, J., The key role of environmental colloids/nanoparticles for the sustainability of life. Environmental Chemistry 2006, 3, (3), 155-158.

78. Yang, Y.; Doudrick, K.; Bi, X.; Hristovski, K.; Herckes, P.; Westerhoff, P.; Kaegi, R., Characterization of food-grade titanium dioxide: the presence of nanosized particles. Environmental science \& technology 2014, 48, (11), 6391-6400.

79. Stark, W. J.; Stoessel, P. R.; Wohlleben, W.; Hafner, A., Industrial applications of nanoparticles. Chemical Society Reviews 2015, 44, (16), 5793-5805.

80. Mitrano, D. M.; Motellier, S.; Clavaguera, S.; Nowack, B., Review of nanomaterial aging and transformations through the life cycle of nano-enhanced products. Environment international 2015, 77, 132-147. 
81. Wagner, S.; Gondikas, A.; Neubauer, E.; Hofmann, T.; von der Kammer, F., Spot the difference: engineered and natural nanoparticles in the environment — release, behavior, and fate. Angewandte Chemie International Edition 2014, 53, (46), 12398-12419.

82. Zhang, Y.; Kang, S.; Allen, S.; Allen, D.; Gao, T.; Sillanpää, M., Atmospheric microplastics: A review on current status and perspectives. Earth-Science Reviews 2020, 203, 103118.

83. Cole, M.; Lindeque, P.; Halsband, C.; Galloway, T. S., Microplastics as contaminants in the marine environment: a review. Marine pollution bulletin 2011, 62, (12), 2588-2597.

84. Pico, Y.; Alfarhan, A.; Barcelo, D., Nano-and microplastic analysis: Focus on their occurrence in freshwater ecosystems and remediation technologies. TrAC Trends in Analytical Chemistry 2019, 113, 409-425. 85. Oberdörster, E., Manufactured nanomaterials (fullerenes, C60) induce oxidative stress in the brain of juvenile largemouth bass. Environmental health perspectives 2004, 112, (10), 1058-1062.

86. Yazdi, A. S.; Guarda, G.; Riteau, N.; Drexler, S. K.; Tardivel, A.; Couillin, I.; Tschopp, J., Nanoparticles activate the NLR pyrin domain containing 3 (Nlrp3) inflammasome and cause pulmonary inflammation through release of IL-1 $\alpha$ and IL-1 $\beta$. Proceedings of the National Academy of Sciences 2010, 107, (45), 19449-19454. 87. Horngren, T.; Kolodziejczyk, B. Microplastic and nanoplastic pollution threatens our environment. How should we respond? https://www.weforum.org/agenda/2018/10/micro-and-nano-plastics-the-next-global-epidemics/ 88. Backhaus, T.; Wagner, M., Microplastics in the environment: Much ado about nothing? A debate. Global Challenges 2018, 1900022.

89. Wigger, H.; Kägi, R.; Wiesner, M.; Nowack, B., Exposure and possible risks of engineered nanomaterials in the environment-current knowledge and directions for the future. Reviews of Geophysics, e2020RG000710.

90. Jesus, S.; Schmutz, M.; Som, C.; Borchard, G.; Wick, P.; Borges, O., Hazard assessment of polymeric nanobiomaterials for drug delivery: what can we learn from literature so far. Frontiers in bioengineering and biotechnology 2019, 7, 261.

91. Hauser, M.; Li, G.; Nowack, B., Environmental hazard assessment for polymeric and inorganic nanobiomaterials used in drug delivery. Journal of nanobiotechnology 2019, 17, (1), 56.

92. Reidy, B.; Haase, A.; Luch, A.; Dawson, K. A.; Lynch, I., Mechanisms of silver nanoparticle release, transformation and toxicity: a critical review of current knowledge and recommendations for future studies and applications. Materials 2013, 6, (6), 2295-2350.

93. Maynard, A. D.; Aitken, R. J., 'Safe handling of nanotechnology'ten years on. Nature nanotechnology 2016, 11, (12), 998-1000.

94. Valsami-Jones, E.; Lynch, I., How safe are nanomaterials? Science 2015, 350, (6259), 388-389.

95. Milosevic, A.; Romeo, D.; Wick, P., Understanding Nanomaterial Biotransformation: An Unmet Challenge to Achieving Predictive Nanotoxicology. Small 2020, 1907650.

96. Stone, V.; Pozzi-Mucelli, S.; Tran, L.; Aschberger, K.; Sabella, S.; Vogel, U.; Poland, C.; Balharry, D.; Fernandes, T.; Gottardo, S., ITS-NANO-Prioritising nanosafety research to develop a stakeholder driven intelligent testing strategy. Particle and fibre toxicology 2014, 11, (1), 9.

97. Grieger, K.; Jones, J. L.; Hansen, S. F.; Hendren, C. O.; Jensen, K. A.; Kuzma, J.; Baun, A., Best practices from nano-risk analysis relevant for other emerging technologies. Nature nanotechnology 2019, 14, (11), 998-1001.

98. Hüffer, T.; Praetorius, A.; Wagner, S.; von der Kammer, F.; Hofmann, T., Microplastic Exposure Assessment in Aquatic Environments: Learning from Similarities and Differences to Engineered Nanoparticles. Environmental science \& technology 2017, 51, (5), 2499-2507.

99. Hristozov, D.; Gottardo, S.; Semenzin, E.; Oomen, A.; Bos, P.; Peijnenburg, W.; van Tongeren, M.; Nowack, B.; Hunt, N.; Brunelli, A., Frameworks and tools for risk assessment of manufactured nanomaterials. Environment international 2016, 95, 36-53.

100. Romeo, D.; Salieri, B.; Hischier, R.; Nowack, B.; Wick, P., An integrated pathway based on in vitro data for the human hazard assessment of nanomaterials. Environment International 2020, 137, 105505.

101. Salieri, B.; Kaiser, J.-P.; Rösslein, M.; Nowack, B.; Hischier, R.; Wick, P., Relative potency factor approach enables the use of in vitro information for estimation of human effect factors for nanoparticle toxicity in life-cycle impact assessment. Nanotoxicology 2020, 14, (2), 275-286.

102. Faria, M.; Björnmalm, M.; Thurecht, K. J.; Kent, S. J.; Parton, R. G.; Kavallaris, M.; Johnston, A. P.; Gooding, J. J.; Corrie, S. R.; Boyd, B. J., Minimum information reporting in bio-nano experimental literature. Nature nanotechnology 2018, 13, (9), 777-785.

103. Fox-Glassman, K. T.; Weber, E. U., What makes risk acceptable? Revisiting the 1978 psychological dimensions of perceptions of technological risks. Journal of Mathematical Psychology 2016, 75, 157-169.

104. Leslie, H.; Depledge, M., Where is the evidence that human exposure to microplastics is safe? Environment International 2020, 142, 105807. 
105. Wardman, T.; Koelmans, A. A.; Whyte, J.; Pahl, S., Communicating the absence of evidence for microplastics risk: Balancing sensation and reflection. Environment International $\mathbf{2 0 2 0 .}$

106. Gouin, T.; Cunliffe, D.; De France, J.; Fawell, J.; Jarvis, P.; Koelmans, A.; Marsden, P.; Testai, E.; Asami, M.; Bevan, R., Clarifying the absence of evidence regarding human health risks to microplastic particles in drinkingwater: High quality robust data wanted. Environment International 2020. 